\title{
Monetary Models of Exchange Rates and Sweep Programs
}

\author{
By \\ Rakesh K. Bissoondeeal, Jane M. Binner, Thomas Elger \\ RP 0635
}

Rakesh K. Bissoondeeal

Economics and Strategy Group, Aston Business School, Aston University, Aston Triangle, Birmingham B4 $7 E T, U K$

Email: r.bissoondeeal@aston.ac.uk, Tel: 44 (0) 121204 3128,Fax: 44 (0) 1212043306

Jane M. Binner

Economics and Strategy Group, Aston Business School, Aston University, Aston Triangle, Birmingham B4 $7 E T, U K$

Email:j.m.binner@aston.ac.uk,Tel: 44 (0) 121204 3036,Fax: 44 (0) 1212043306

Thomas Elger

Department of Economics, Lund University, P.O. Box 7082, SE-220 07 Lund, Sweden

Email:Thomas.elger@nek.lu.se,Tel:46(0)462227919

December 2006

ISBN No: 1854496395

Aston Academy for Research in Management is the administrative centre for all research activities at Aston Business School. The School comprises more than 70 academic staff organised into thematic research groups along with a Doctoral

Programme of more than 50 research students. Research is carried out in all of the major areas of business studies and a number of specialist fields. For further information contact:

The Research Director, Aston Business School, Aston University, Birmingham B4 7ET

Telephone No: (0121) $2043000 \quad$ Fax No: (0121) 2043326 http://www.abs.aston.ac.uk/

Aston Business School Research Papers are published by the Institute to bring the results of research in progress to a wider audience and to facilitate discussion. They will normally be published in a revised form subsequently and the agreement of the authors should be obtained before referring to its contents in other published works. 


\title{
Running title: Forecasting Exchange Rates with Monetary Models
}

\begin{abstract}
Numerous studies find that monetary models of exchange rates cannot beat a random walk model. Such a finding, however, is not surprising given that such models are built upon money demand functions and traditional money demand functions appear to have broken down in many developed countries. In this paper we investigate whether using a more stable underlying money demand function results in improvements in forecasts of monetary models of exchange rates. More specifically, we use a sweep-adjusted measure of US monetary aggregate M1 which has been shown to have a more stable money demand function than the official M1 measure. The results suggest that the monetary models of exchange rates contain information about future movements of exchange rates but the success of such models depends on the stability of money demand functions and the specifications of the models.
\end{abstract}

Keywords: monetary models of exchange rates, sweep programs, forecasting ${ }^{\mathrm{a} C}$ Corresponding author 


\section{Introduction}

Exchange rate forecasting is of great interest to academics given its importance to financial market participants and policymakers. For example, in countries with inflation targeting, forecasts of exchange rates can play an important role in guiding monetary policy since changes in exchange rates can affect prices both directly, through their impact on import prices, and indirectly, through their effects on trade. Since the breakdown of the Bretton Woods system of fixed exchange rates and the implementation of the floating exchange rate system in 1971, researchers have incessantly tried to forecast exchange rates. During these years, with the increase in computing power, a variety of estimation techniques have also been developed. However, a large number of studies argue that such models fail to improve on the forecasts of a (naïve) random walk model. An example is Newbold et al. (1998) but perhaps, the most widely cited paper in that respect is Meese and Rogoff (1983). Such a finding implies that there is no connection between the menu of economic or financial fundamentals that economic theory suggests should drive the exchange rates. However, when the results of Meese and Rogoff (1983) are viewed against the behaviour of monetary aggregates in developed countries, such as the US, the results do not seem surprising. Monetary models of exchange rates are built upon money demand functions and rest on the assumption of stability of these functions. However, in the 1980 s, due to financial innovations, money demand functions broke down in many developed countries (see for example, Binner et al. (2002)). Smith and Wickens (1986), for example, argue that misspecification of the money demand function is a very important cause for the breakdown of monetary models of exchange rates. In the literature very little attention has been paid to the potential 
misspecification in monetary models of exchange rates caused by instability in money demand functions. Among the notable few is Chrystal and MacDonald (1995), who find that borrowing from the recent developments in monetary aggregation theory, aimed at improving the underlying the money demand functions, can lead to improvements in forecasts from monetary models of exchange rates.

Given the sparse literature on the link between misspecifications in monetary models of exchange rates and misspecifications in underlying money demand functions, this study adds to the literature by investigating whether the forecasting performance of monetary models can be improved by using a more stable underlying money demand function. The focus will be on the stability of US monetary aggregate M1, as it is used in the overwhelming majority of studies on monetary models of exchange rates. Some recent examples are, Francis et al. (2001), Qi and Wu (2003) and Cuaresma and Hlouskova (2005). An important innovation, however, will be to use US M1 data that has been adjusted to account for the introduction of sweep programs in the US in the mid 1990s. The latter has distorted the official M1 data, as discussed in a series of recent papers, and has contributed to further instability in US money demand functions, see, for example, Dutkowsky and Cynnamon (2003) and Jones et al. (2005). The findings of Dutkowsky and Cynnamon (2003) indicate that adding sweep balances to US M1 gives an empirically reliable money demand function. Our hypothesis, therefore, is that accounting for the distortion caused by sweep programs should lead to improved monetary models of exchange rates. 
The rest of the paper is organized as follows. The next section provides an overview of the sweep programs in the US. Section 3 derives the basic monetary models of exchange

rate. Section 4 presents the econometric methods for forecasting. Section 5 presents the data and carries out some preliminary investigation. The estimation results and discussions are presented in Section 6. Section 7 presents a summary and the conclusions.

\section{Sweep Programs}

We examine the effects of two types of sweep programs in the US- retail sweep programs and commercial demand deposit sweep programs, on monetary models of exchange rates.

In a retail sweep program, banks move excess forecasted funds out of their customers' checkable deposit accounts into money market deposit accounts (MMDAs) as part of savings account. Funds in checkable deposits are subject to reserve requirements whereas MMDAs have zero statutory reserve requirements. Retail sweeping is beneficial to banks as they can loan out funds which would have otherwise been held as reserves. As discussed in Dutkowsky and Cynamon (2003), retail sweeping distorts M1 as a measure of transactions money. The sweeping process is literally invisible to the customer and therefore it is very unlikely that banks would voluntarily pass on any earnings from this process to their customers (Anderson and Rasche, 2001). The invisibility of the sweeping process also means that it does not change the customers' perceived amount of transactions deposits. And customers have unrestricted access to swept and unswept funds. However retail sweeps affect the amount of transaction deposits reported by banks to the Federal Reserve as swept funds are reported as part of MMDAs when they have the 
same services as checkable deposits. Thus M1 under reports transaction deposits (narrow money).

The distortion of M1 as a measure of transactions money is exacerbated by commercial demand deposit (DD) sweep programs. Treasury Strategies (1995) define a commercial DD sweep account as a “...service that automatically links a commercial depository account with an investment account, and, without customer intervention, adjusts depository account balances to a predetermined target level by transferring funds to or from the investment account as needed." As opposed to the retail sweeping this type of sweeping is not invisible to the customer, the bank's business customers are aware that they own such assets. Both banks and customers benefit from the commercial DD sweep program. Banks benefit by recapturing lost funds when customers consolidate their accounts at a single bank, reducing required reserves and FDIC premiums, and deriving income from fees. Whereas customers receive much of the earnings from the sweeping (see. e.g. Treasury Strategies, 1995). Although swept funds are not checkable in a legal sense, competitive pressures force banks to increase the liquidity of swept funds. For example, writings on commercial DD sweep programs suggest that banks allow customers to write checks against their entire account balance (swept and unswept funds). As stated by Treasury Strategies (1997) customers of sweep accounts can be fully invested and yet have the same-day access to invested funds. This implies that that these swept balances should be treated as checkable deposits within the monetary aggregates. However, swept funds commercial DD sweep programs are reported to the Federal 
Reserve as part of the linked investment accounts rather than DDs, resulting in further distortion of M1.

A sensible measure of transactions deposits should, therefore, include swept funds in retail sweep programs and commercial DD programs.

\section{Money and exchange rates}

Several versions of monetary models of exchange rates have been put forward, giving rise to two main types of models that are widely used in the literature. The first one is the flexible price (FP) model of Frenkel (1976) and Bilson (1978). The second is the sticky price (SP) model based on the work of Dornbusch (1976) and Frankel (1979). Both models depend on two major building blocks: the purchasing power parity (PPP) relation is assumed to hold and the existence of a stable money demand function. In the FP model the PPP is assumed to hold at all times so that the exchange rate adjusts instantaneously to equate the relative prices of domestic and foreign goods. The PPP relation is given by

$$
s_{t}=p_{t}-p_{t}^{*}
$$

where $s_{t}$ is the nominal exchange rate representing the number of home (US) currency per units of foreign (UK/Euro) currency, $p_{t}$ is the price level, an $*$ denotes a foreign variable, all the variables are transformed using the natural logarithm.

The second building block of the models assumes a stable demand for money function in both countries. Starting from the standard Cagan (1956) money demand relationship of 
the form $M^{D}=Y^{\alpha_{1}} \exp ^{-\alpha_{2} i}$ let money demand relationships for the domestic country and foreign country, respectively, be

$$
\begin{aligned}
& m_{t}-p_{t}=\alpha_{1}^{1} y_{t}-\alpha_{2}^{1} I_{t} \\
& m_{t}^{*}-p_{t}^{*}=\alpha_{1}^{*} y_{t}^{*}-\alpha_{2}^{*} I_{t}^{*}
\end{aligned}
$$

where $m_{t}$ denotes the money supply, $p_{t}$ the price level and $y_{t}$ real income and $I_{t}$ is an interest rate and $\alpha_{1}, \alpha_{2}>0, \alpha_{1}$ is the income elasticity of demand for money and $\alpha_{2}$ is interest rate semielasticity, an * denotes a foreign variable. The lower case letters denote that a variable has been transformed by using the natural logarithm. Equations 1, 2 and 3 yield the basic FP monetary model:

$$
s_{t}=\left(m_{t}-m_{t}^{*}\right)-\alpha_{1}^{1}\left(y_{t}-y_{t}^{*}\right)+\alpha_{2}^{1}\left(I_{t}-I_{t}^{*}\right)
$$

Equation 4 assumes that the income elasticities and interest rate semielasticities in the money demand functions are the same across countries. A more flexible variant of Equation 4, given below, is usually estimated where the one-to-one relationship between $s_{t}$ and $\left(m_{t}-m_{t}^{*}\right)$ is relaxed (see, for example, Chen (2004))

$$
s_{t}=\alpha_{0}^{2}\left(m_{t}-m_{t}^{*}\right)-\alpha_{1}^{2}\left(y_{t}-y_{t}^{*}\right)+\alpha_{2}^{2}\left(I_{t}-I_{t}^{*}\right)
$$

The SP model is based on the work of Dornbusch (1976) and Frankel (1979). It differs from the flexible price model in the sense that prices are rigid and adjust gradually so that the PPP relation holds only in the long run. The SP model is of the following form:

$$
s_{t}=\alpha_{0}^{3}\left(m_{t}-m_{t}^{*}\right)-\alpha_{1}^{3}\left(y_{t}-y_{t}^{*}\right)-\alpha_{2}^{3}\left(I_{t}-I_{t}^{*}\right)+\alpha_{3}^{3}\left(\pi_{t}-\pi_{t}^{*}\right)
$$

where $\pi_{t}$ is the expected inflation proxied by past inflation rates or assuming rational expectations, future inflation rates (Frenkel and Koske, 2004) and $\alpha_{0}^{3}, \alpha_{1}^{3}, \alpha_{2}^{3}$ and $\alpha_{3}^{3}>0$. 
The FP and SP models are the two most commonly used models in monetary exchange rate model studies. These models, however, constrain the relevant elasticities in the money demand functions to be equal across countries. These restrictions are generally not imposed for theoretical reasons but to reduce multicollinearity (Haynes and Stone, 1981). Rasulo and Wilford (1980) show that if the relevant elasticities are not identical, such constraints introduce a serious bias that affects all the coefficients in the monetary models of exchange rates. Also, Haynes and Stone (1981) highlight that such restrictions are problematic in the sense the specification bias which results from them can lead to sign reversal in the constrained coefficient. In the light of this, some researchers estimate unconstrained versions of (5) and (6) of the following forms respectively (see, for example, Tawadros (2001)).

$$
\begin{aligned}
& s_{t}=\gamma_{1}^{1} m_{t}+\gamma_{2}^{1} m_{t}^{*}+\gamma_{3}^{1} y_{t}+\gamma_{4}^{1} y_{t}^{*}+\gamma_{5}^{1} I_{t}+\gamma_{6}^{1} I_{t}^{*} \\
& s_{t}=\gamma_{1}^{2} m_{t}+\gamma_{2}^{2} m_{t}^{*}+\gamma_{3}^{2} y_{t}+\gamma_{4}^{2} y_{t}^{*}+\gamma_{5}^{2} I_{t}+\gamma_{6}^{2} I_{t}^{*}+\gamma_{7}^{2} \pi_{t}+\gamma_{8}^{2} \pi_{t}^{*}
\end{aligned}
$$

where the expected signs of the coefficients are as follows: $\gamma_{1}^{1}, \gamma_{4}^{1}, \gamma_{5}^{1}>0 ; \gamma_{2}^{1}, \gamma_{3}^{1}, \gamma_{6}^{1}<0$ and $\gamma_{1}^{2}, \gamma_{4}^{2}, \gamma_{6}^{2}, \gamma_{7}^{2}>0$ and $\gamma_{2}^{2}, \gamma_{3}^{2}, \gamma_{5}^{2}, \gamma_{8}^{2}<0$ (see, for example, Tawadros (2001)).

Nevertheless, there is a trade-off between the gain in precision resulting from decrease in multicollinearity and loss in efficiency by constraining the variables to have the same elasticity across different countries. We therefore estimate both the constrained and unconstrained versions of the FP and SP models. In what follows we refer to models constructed using sweep-adjusted US M1 as sweep-adjusted models and those constructed using official US M1 as unadjusted models and a list of abbreviations for the different monetary models is given in Table 1. 


\section{[Table 1 about here]}

\section{Econometric methodology}

The monetary models used in this paper will be developed using two important models used in the forecasting literature: vector autoregressive models specified in first differences (DVAR) and vector error correction (VEC) models. The DVAR( $k$ ) model has been used for exchange rate forecasting in, for example, Cuaresma and Hlouskova (2005) and can be represented as follows:

(8) $\Delta z_{t}=\sum_{i=1}^{k-1} \Gamma_{i} \Delta z_{t-i}+\varepsilon_{1 t}$

where $k$ is the number of lags in the $\mathrm{VAR}, z_{t}$ is a $p \times 1$ vector of variables, $\Gamma_{i} \mathrm{~s}$ are coefficient matrices and $\varepsilon_{1 t}$ is a vector of Gaussian error terms. The VEC model has been used for exchange rate forecasting in, for example, McCrae et al. (2002) and can be represented as follows:

(9) $\quad \Delta z_{t}=\sum_{i=1}^{m-1} \widetilde{\Gamma}_{i} \Delta z_{t-i}+\Pi z_{t-1}+\varepsilon_{2 t}$

where $\widetilde{\Gamma}_{i} \mathrm{~s}$ and $\Pi$ are coefficient matrices, $\varepsilon_{2 t}$ is a vector of Gaussian error terms. Let $r=\operatorname{rank}(\Pi)$ and $p$ be the number of variables in $z_{t}$, then if $0<r<p$ the matrix $\Pi$ can be partitioned into $p \times r$ matrices $\alpha$ and $\beta$ such that $\Pi=\alpha \beta^{\prime}$ and $\beta^{\prime} z_{t}$ is $\mathrm{I}(0)$ (Johansen and Juselius, 1990). $r$ is the number of cointegrating relationships and each column of $\beta$ is the cointegrating vector. In this study the trace test (see, Johansen (1995) is used to determine the number of cointegrating relationships between the exchange rates and their fundamentals. 
The monetary forecasting models are compared to a random walk model of the following form

$$
s_{t}=s_{t-1}+\varepsilon_{3 t}
$$

which implies that the best prediction for the exchange rate would be the same as this period's exchange rate.

\section{Data and preliminary analysis}

The data used in this study are quarterly data for the period 1986Q4 to 2004Q1 and are reported in Table 2. The starting period corresponds to the earliest observation on UK M1 data available on Datastream and the ending period is constrained by the availability of sweep-adjusted data for the US M1.

The stationarity properties of the variables used in this study are checked using the Augmented Dickey and Fuller (ADF) (1989) test. The results, not reported here for reasons of brevity, suggest that the variables appear to be I(1) variables and hence valid candidates for cointegration analysis.

The in-sample period is 1986Q4 to 2002Q1 which is used for parameter estimation. Since a period of about two years is quite commonly left out for out-of-sample forecast evaluation (see, for example, Binner et al.(2005)), a similar strategy is adopted here and thus the remaining two years of data are left out for out-of-sample forecast evaluation. 


\section{Estimation results}

\subsection{Cointegrating results}

The specifications of every system used in estimating the cointegrating vectors are given in Tables A1 and A2 of Appendix A. Results from the trace tests, presented in Table B1 through to Table B4 in Appendix B, suggest that there exists at least one cointegrating vector for each model. The existence of cointegrating vectors between the exchange rates and the set of macroeconomic variables provides strong support for monetary models (see, for example, Francis et al. (2001)). In the case of, for example, the USP model for US dollar/UK pound rate, there exist eight cointegrating vectors, therefore, for reasons of parsimony, the restriction of one cointegrating vector is imposed on each of the VEC forecasting models; following forecasting studies like Binner et al. (2005). Thus, the first cointegrating vector from each system is reported in Tables 3 and 4 . The signs of many of the variables in the cointegrating vectors do not conform to economic theory, however, this is not uncommon in the literature (see, for example, Francis et al. (2001), Tawadros, 2001)).

\section{[Table 3 about here]}

\subsection{Forecasting}

Following studies which use money for forecasting, such as Elger et al. (2006), Schunk (2001), we allow for two lags of the endogenous variables in the DVAR and VEC models. The models are evaluated using the following three performance measures: RMSE/RMSE(RW), MAE/MAE(RW) and MAPE/MAPE(RW), where RMSE is the root mean square error, MAE is the mean absolute error and MAPE is the mean absolute percentage error (MAPE). To discriminate between two models, the one which performs 
better across at least two of the performance measures is considered as the better model. Thus if a model has at least two of the performance measures less than one then it has a better forecasting power than the random walk model and the closer the performance measures to zero the better the model is. To make the MAPE comparable across every model, the forecasts of the levels are retrieved from the forecasts of the first differences. The forecasting performances for the various models are presented in Tables 5 and 6 .

\section{[Table 5 about here]}

[Table 6 about here]

\section{DVAR forecasts for US dollar/UK pound rate}

We begin our discussion with results from DVAR models. According to the three performance measures, we find that all the monetary models perform better than the random walk model. We also find that the sweep-adjusted models perform consistently better than their unadjusted counterparts. Such a finding lends support to monetary models of exchange rates and our hypothesis that better forecasts can be obtained from monetary models of exchange rates if the underlying money demand function is more stable.

\section{VEC forecasts for US dollar/UK pound rate}

The VEC model performs better than the RW model in five out of eight comparisons. On comparing the two measures of money, we find that both perform equally well in the sense that each one performs better than the other in two out of four comparisons. 
We also note that in five out of eight comparisons the VEC model does not improve on its corresponding DVAR model. In theory, one would expect the VEC model to perform better than the DVAR model (see, Engle and Yoo, 1989) and studies, for example, Lesage (1990), support this argument. However, there are also a number of studies which find that the error correction term does not always improve the out of sample forecasts of VEC models (see, for example, Copeland and Wang, 2000). Thus in the three cases where VEC monetary models fail to improve on RW forecasts and the two cases where the sweep-adjusted models perform less well than the unadjusted models, it is very likely that the relative poor performance is due to a model specification problem rather than the different monetary models not conforming with theory. This argument is strengthened by the fact that the forecasts from the corresponding DVAR models all conform to the relevant theories.

In general we also find that the unconstrained models have a better forecasting performance than the constrained models and overall sticky price models provide more accurate forecasts than flexible price models.

\section{DVAR forecasts for US dollar/Euro rate}

In four out of eight comparisons the monetary models do not perform better than the RW model. Out of the four better performing models three of them are sweep-adjusted models. Thus, three out of four sweep-adjusted DVAR models perform better than the RW models. The evidence here to some extent can help explain the lack of link between exchange rates and variables, such as money, that economic theory suggests should drive 
exchange rates. According to the results the sweep-adjusted models are more likely to beat random walk forecasts than unadjusted models. The better performance of the sweep-adjusted monetary DVAR models is most probably due to such models having a better underlying money demand specification. The implication is that monetary models do contain information about future movements of exchange rates, however, not using right measure of money can result in unstable underlying money demand specifications; as a consequence of which monetary models will not always beat random walk models. The case for sweep-adjusted models is further strengthened by the fact that every sweepadjusted model performs better than its unadjusted counterpart.

\section{VEC forecasts for US dollar/Euro rate}

The VEC model performs better than the RW model in only one case. However, as in the case of the US dollar/ UK pound case, the performance of the VEC models in general is poorer than DVAR forecasts. Thus, the poor performance of the VEC monetary models can be attributed to some extent to a model specification problem. The only VEC model performing better than the RW model is a sweep-adjusted model and we find that every sweep-adjusted model performs better than its corresponding unadjusted model.

Overall, unconstrained models perform better than the constrained models and sticky price models have a better performance than flexible price models. 


\section{Analysis of forecast performance of various models}

We find that the monetary models can beat random walk models. However, according to this study, the success of monetary models depends on a number of factors:

Firstly, on the underlying money demand functions. For both exchange rates we find that in general sweep-adjusted models have a better performance than unadjusted models. The better performance is likely to have stemmed from the fact that sweep-adjusted US M1 has a more stable money demand function than the official US M1 data, as shown by Dutkowsky and Cynnamon (2003).

Secondly, on model specifications. In this paper we find that there are differences in forecasts generated by different specifications of monetary models. The DVAR model in general provides better forecasts than VEC models. Overall, unconstrained models perform better than constrained models and sticky price models provide more accurate forecasts than flexible price models.

The best model in the case of the US dollar/UK pound rate is an unconstrained sticky price sweep-adjusted DVAR model. Looking at the RMSE, for example, it improves the forecast accuracy by $28.6 \%$ over the random walk model. The model provides an $11.5 \%$ improvement in forecast accuracy over the best unadjusted monetary model. In the case of the US dollar/Euro rate also the best model is an unconstrained sticky price sweepadjusted DVAR model. It provides a 5.2\% improvement in forecasting accuracy over the random walk model and $1.3 \%$ improvement in forecasting accuracy over the best 
unadjusted monetary model. The actual series and the forecasted values from these two models are presented in Figure 1.

\section{[Figure 1 about here]}

\section{Summary and Conclusions}

A well cited finding in the literature of exchange rate forecasting is that of Meese and Rogoff (1983) who find that random walk models perform better than monetary models in out-of-sample forecasting. Such a finding, however, is not surprising when viewed against the background of the behaviour of monetary aggregates in major countries such as the US. Traditional money demand functions appear to have broken down due to financial innovation. Since the monetary models of exchange rates depend on underlying money demand functions, it is therefore not surprising that monetary models that performed well in the early 1970 s broke down in the early 1980s. In this paper we investigate whether improving the underlying money demand functions can result in improvements in forecasting accuracy of monetary models of exchange rates. More specifically, we use sweep-adjusted US M1 which has been shown to have a more stable money demand function than the official unadjusted US M1.

This study provides support for monetary models of exchange rates in two ways. Firstly, we find the existence of at least one cointegrating relationship for every monetary model considered. Such a finding suggests that there is a link between exchange rates and the set of economic variables that theory suggests should be driving the exchange rates. Secondly, the results suggest that monetary models of exchange rate can beat random walk models in out-of-sample forecasting. However, the performance of such models 
depends on, firstly, the model specifications, such as whether DVAR or VEC models, unconstrained or constrained models or flexible price or sticky price models are used. Secondly and more importantly, however, the results suggest that an improved underlying money demand specification, resulting from the use of sweep-adjusted data in this case, leads to improvements in forecasting accuracy of monetary models of exchange rate. Such a finding corroborates the findings of Chrystal and MacDonald (1995) who find that borrowing from recent developments in monetary aggregation literature, aimed at improving the underlying money demand specifications of monetary models of exchange rate, results in improvements in forecasting accuracy such models. 


\section{REFERENCES}

Anderson, R. and Rasche, R. (2001) Retail sweep programs and bank reserves: 19941999, Federal Reserve Bank of St. Louis Review, 83, 51-72.

Bilson, J.F. (1978) The monetary approach to the exchange rate: some empirical evidence, International Monetary Fund Staff Papers, 25, 201-23.

Binner, J.M. Gazely, A.M. and Chen, S. (2002) Financial innovation and Divisia monetary indices: a neural network approach, The European Journal of Finance, 8, 23847.

Binner J.M., Bissoondeeal, R.K., Elger T., Gazely A.M. and Mullineux, A.W. (2005) A comparison of linear forecasting models and neural networks; an application to Euroinflation and EuroDivisia, Applied Economics, 2005, 37, 665-80.

Cagan, P. (1956) The monetary dynamics of hyperinflation, in Studies in the Quantity theory of money, ed. M. Friedman, Chicago, University of Chicago.

Cuaresma, J.C. and Hlouskova, J. (2005) Beating the random walk in central and eastern Europe, Journal of Forecasting, 24, 189-201.

Chen, Y. (2004) Exchange rates and fundamentals: Evidence from commodity prices, mimeo-graph, Harvard University.

Chrystal, K.A. and MacDonald, R. (1995) Exchange rates, financial innovation and Divisia money: the sterling/dollar rate 1972-1990, Journal of International Money and Finance, 14, 493-513. 
Copeland, L. and Wang, P. (2000) Forecasting the returns on UK investment trusts: a comparison, The European Journal of Finance, 6, 298-310.

Cynamon, B., Dutkowsky, D. and Jones, B. (forthcoming) Redefining the monetary aggregates: a clean sweep, Eastern Economic Journal

Dickey, D.A. and Fuller, W.A. (1979) Distribution of the estimators for autoregressive time series with a unit root, Journal of the American Statistical Association, 74, 427-31.

Dornbusch, R. (1976) Expectations and exchange rate dynamics, Journal of Political Economy, 84, 1161-76.

Dutkowsky, D. and Cynamon, B. (2003) Sweep programs: the fall of M1 and the rebirth of the medium of exchange, Journal of Money, Credit, and Banking, 35, 263-80.

Elger, T., Jones, B.E., and Nilsson, B. (2006) Forecasting with monetary aggregates recent evidence for the United States, Journal of Economics and Business, 58, 428-46.

Engle, R.F. and Yoo, B.S. (1987) Forecasting and testing in cointegrated systems, Journal of Econometrics, 35, 143-59.

Francis, B., Hasan, I. and Lothian, J.R. (2001) The monetary approach to exchange rates and the behaviour of the Canadian dollar over the long run, Applied Financial Economics, 11, 475-81.

Frankel, J.A. (1979) On the mark: a theory of floating exchange rates based on real interest rate differentials, American Economic Review, 69, 610-22. 
Frenkel, J.A. (1976) A monetary approach to the exchange rate: doctrinal aspects and empirical evidence, Scandinavian Journal of Economics, 78, 200-24.

Frenkel, M. and Koske, I. (2004) How well can monetary factors explain the exchange rate of Euro, Atlantic Economic Journal, 32, 232-43.

Haynes, S.E. and Stone, J.A. (1981) On the mark: a comment, American Economic Review, 78, 200-24.

Johansen, S. (1995) Likelihood-Based Inference in Cointegrated Vector Autoregressive Models, Oxford University Press, Oxford.

Johansen, S. and Juselius, K. (1990) Maximum likelihood estimation and inference on cointegration with application to the demand for money, Oxford Bulletin of Economics and Statistics, 52, 169-209.

Jones, B., Dutkowsky, D. and Elger, T. (2005) Sweep programs and optimal monetary Aggregation, Journal of Banking and Finance, 29, 483-508.

Lesage, J.P. (1990) A comparison of the forecasting ability of ECM and VAR models, Review of Economics and Statistics, 72, 664-71.

McCrae, M., Lin, Y., Pavlik, D. and Gulati, C. (2002) Can cointegration-based forecasting outperform univariate models? An application to Asian exchange rates, Journal of forecasting, 21, 355-80. 
Meese, R.A. and Rogoff, K. (1983) Empirical exchange rate models of the seventies: Do they fit out of sample? Journal of International Economics, 14, 3-24.

Newbold, P. Rayner, T. Kellard, N. and Ennew, C. (1998) Is the dollar/ECU exchange rate a random walk? Applied Financial Economics, 8, 553-58.

Qi, M. and $\mathrm{Wu}, \mathrm{Y}$. (2003) Nonlinear prediction of exchange rates with monetary fundamentals, Journal of Empirical Finance, 10, 623-40.

Rasulo, J.A. and Wilford, D.S. (1980) Estimating monetary models of balance of payments and exchange rates: a bias, Southern Economic Journal, 47, 136-46.

Schunk, D. (2001) The relative forecasting performance of the Divisia and Simple Sum monetary aggregates, Journal of Money, Credit and Banking, 33, 272-83.

Smith, P.N and Wickens, M.R. (1986) An empirical investigation into the causes of the failure of the monetary model of the exchange rate, Journal of Applied Econometrics, 1, $143-62$

Stracca, L. (2004) Does liquidity matter? Properties of a Divisia monetary aggregate in the Euro area, Oxford Bulletin of Economics and Statistics, 66, 309-31. 
Tawardros, G.B. (2001) The predictive power of the monetary model of exchange rate determination, Applied Financial Economics, 11, 279-86.

Treasury Strategies (1995) Commercial banking sweep account survey results.

Treasury Strategies (1997) Commercial banking sweep account survey results. 


\section{Table captions}

Table 1: Abbreviations for monetary models

Table 2: Data characteristics and sources

Table 3: Cointegrating vectors of US dollar/UK pound rate models (1986Q4 to 2002Q1)

Table 4: Cointegrating vectors of US dollar/Euro rate models (1986Q4 to 2002Q1)

Table 5: Out-of-sample forecasting performance of US dollar/UK pound rate models (2002Q2 to 2004Q1)

Table 6: Out-of-sample forecasting performance of US dollar/Euro rate models (2002Q2 to 2004 Q1) 
Table 1: Abbreviations for monetary models

\begin{tabular}{|l|c|c|}
\hline & Unadjusted models & Sweep-adjusted models \\
\hline Constrained flexible price & CFP & CFPS \\
\hline Constrained sticky price & CSP & CSPS \\
\hline Unconstrained flexible price & UFP & UFPS \\
\hline Unconstrained sticky price & USP & USPS \\
\hline
\end{tabular}


Table 2: Data characteristics and sources

Panel A: US variables

\begin{tabular}{|l|l|l|}
\hline \multicolumn{2}{|l|}{ Variables } & \multicolumn{1}{c|}{ Data source } \\
\hline Exchange rates $\left(s_{t}\right)$ & $\begin{array}{l}\text { (1) US dollar/ UK pound rate } \\
\text { (2) US dollar/ Euro rate }\end{array}$ & $\begin{array}{l}\text { Datastream } \\
\text { Datastream }\end{array}$ \\
\hline Money supply $\left(m_{t}\right)$ & $\begin{array}{l}\text { (1) US monetary aggregate M1 } \\
\text { (2) Sweep-adjusted US M1 }\end{array}$ & $\begin{array}{l}\text { FRED } \\
\text { Cynamon } \text { et al. } \\
\text { (forthcoming) }\end{array}$ \\
\hline Output $\left(y_{t}\right)$ & Real gross domestic product & Datastream \\
\hline $\begin{array}{l}\text { Short-term interest rate } \\
\left(I_{t}\right)\end{array}$ & Treasury bill rate & Datastream \\
\hline Price level $\left(p_{t}\right)$ & Consumer price index & Datastream \\
\hline
\end{tabular}

Panel B: UK variables

\begin{tabular}{|l|l|l|}
\hline \multicolumn{2}{|c|}{ Variables } & \multicolumn{1}{c|}{ Data source } \\
\hline Money supply $\left(m_{t}\right)$ & UK monetary aggregate M1 & Datastream \\
\hline Output $\left(y_{t}\right)$ & Real gross domestic product & Datastream \\
\hline $\begin{array}{l}\text { Short-term interest rate } \\
\left(I_{t}\right)\end{array}$ & Treasury bill rate & Datastream \\
\hline Price level $\left(p_{t}\right)$ & Consumer price index & Datastream \\
\hline
\end{tabular}

Panel C: Euro area variables

\begin{tabular}{|l|l|l|}
\hline \multicolumn{2}{|c|}{ Variables } & \multicolumn{1}{c|}{ Data source } \\
\hline Money supply $\left(m_{t}\right)$ & Euro area monetary aggregate M1 & Datastream \\
\hline Output $\left(y_{t}\right)$ & Real gross domestic product & Datastream \\
\hline $\begin{array}{l}\text { Short-term interest rate } \\
\left(I_{t}\right)\end{array}$ & Money market rate & Stracca $(2004)^{3}$ \\
\hline Price level $\left(p_{t}\right)$ & Consumer price index & Datastream \\
\hline
\end{tabular}

Notes:

(1) Apart from the interest rates, all series are seasonally adjusted.

(2) The lower case letters $\left(m_{t}, y_{t}, p_{t}\right)$ denote that a variable has been transformed by using the natural logarithm. 
Table 3: Cointegrating vectors of US dollar/UK pound rate models (1986Q4 to 2002Q1)

Panel A: Cointegrating vectors for constrained models of US dollar/UK pound rate

\begin{tabular}{lllllll}
\hline & $s_{t}$ & $m_{t}-m_{t}^{*}$ & $y_{t}-y_{t}^{*}$ & $I-I_{t}^{*}$ & $\pi_{t}-\pi_{t}^{*}$ & constant \\
\hline CFP & 1.000 & -0.094 & -23.035 & 8.323 & - & 84.674 \\
CFPS & 1.000 & -0.521 & -20.383 & 5.355 & - & 72.428 \\
CSP & 1.000 & -0.081 & 3.014 & -1.697 & 4.499 & -12.100 \\
CSPS & 1.000 & -0.161 & 1.104 & -0.838 & 4.487 & -5.417 \\
\hline
\end{tabular}

Panel B: Cointegrating vectors for unconstrained models of US dollar/UK pound rate

\begin{tabular}{llllllllllc}
\hline & $s_{t}$ & $m_{t}$ & $m_{t}^{*}$ & $y_{t}$ & $y_{t}^{*}$ & $I_{t}$ & $I_{t}^{*}$ & $\pi_{t}$ & $\pi_{t}^{*}$ & constant \\
\hline UFP & 1.000 & 1.372 & 0.761 & -7.593 & 5.316 & 1.061 & 7.123 & - & - & 9.554 \\
UFPS & 1.000 & -4.338 & 4.055 & -2.384 & -2.582 & -7.284 & -5.955 & - & - & -6.923 \\
& & & & - & & & & & & \\
USP & 1.000 & -0.794 & 1.185 & 33.958 & 29.196 & 47.682 & 7.853 & -23.596 & -53.293 & 119.486 \\
USPS & 1.000 & -10.770 & 7.019 & -9.414 & 6.172 & 8.268 & -18.202 & -22.804 & -16.666 & 28.370 \\
\hline
\end{tabular}

Notes:

(1) $\pi_{t}$ is the inflation rate computed as $p_{t}-p_{t-4}$.

(2) $p_{t}$ and other variables used in Table 3 are defined in Table 2.

(3) An* denotes a foreign variable.

(4) The model abbreviations are explained in Table 1.

(5) The estimations are carried out using CATS and RATS. 
Table 4: Cointegrating vectors of US dollar/Euro rate models ((1986Q4 to 2002Q1)

Panel A: Cointegrating vectors for constrained models of US dollar/Euro rate

\begin{tabular}{lllllll}
\hline & $s_{t}$ & $m_{t}-m_{t}^{*}$ & $y_{t}-y_{t}^{*}$ & $I-I_{t}^{*}$ & $\pi_{t}-\pi_{t}^{*}$ & constant \\
\hline CFP & 1.000 & -0.416 & 11.140 & -18.256 & - & 57.021 \\
CFPS & 1.000 & 0.340 & 8.717 & -8.814 & - & 44.926 \\
CSP & 1.000 & -1.259 & 7.157 & -33.180 & 71.231 & 35.808 \\
CSPS & 1.000 & 1.564 & 8.002 & -5.359 & -15.465 & 41.429 \\
\hline
\end{tabular}

Panel B: Cointegrating vectors for unconstrained models of US dollar/Eurorate

\begin{tabular}{lllllllllll}
\hline & $s_{t}$ & $m_{t}$ & $m_{t}{ }^{*}$ & $y_{t}$ & $y_{t}^{*}$ & $I_{t}$ & $I_{t}^{*}$ & $\pi_{t}$ & $\pi_{t}^{*}$ & constant \\
\hline \multirow{2}{*}{ UFP } & 1.000 & 1.920 & -6.978 & 8 & 8.670 & 40.590 & 17.787 & - & - & 104.252 \\
UFPS & 1.000 & 4.197 & -4.311 & 1.649 & 3.174 & -9.347 & 17.120 & - & - & -37.972 \\
& & & & - & & & & & & \\
USP & 1.000 & -2.220 & 15.437 & 4.340 & -41.954 & 23.777 & 22.286 & -16.237 & -10.402 & 325.237 \\
& & & & - & - & & & & - & \\
USPS & 1.000 & -14.847 & 54.339 & 6.973 & 127.355 & 59.082 & 70.120 & -47.171 & 103.489 & 967.910 \\
\hline
\end{tabular}

Notes:

(1) $\pi_{t}$ is the inflation rate computed as $p_{t}-p_{t-4}$.

(2) $p_{t}$ and other variables used in Table 4 are defined in Table 2.

(3) An* denotes a foreign variable.

(4) The model abbreviations are explained in Table 1.

(5) The estimations are carried out using CATS and RATS. 
Table 5: Out-of-sample forecasting performance of US dollar/UK pound rate models (2002Q2 to 2004Q1)

\begin{tabular}{l|cc|cc|cc}
\hline & \multicolumn{2}{|c|}{ RMSE/RMSE(RW) } & \multicolumn{2}{c|}{ MAE/MAE/(RW) } & \multicolumn{2}{c}{ MAPE/MAPE(RW) } \\
\hline & DVAR & VEC & DVAR & VEC & DVAR & VEC \\
\hline CFP & 0.935242 & 1.092906 & 0.924903 & 1.078473 & 0.921438 & 1.073236 \\
CFPS & 0.937714 & 1.036349 & 0.921854 & 1.019577 & 0.916112 & 1.013316 \\
CSP & 0.922119 & 0.844689 & 0.921854 & 0.862114 & 0.921438 & 0.852197 \\
CSPS & 0.924116 & 1.029859 & 0.918859 & 0.974323 & 0.917443 & 0.938748 \\
UFP & 0.864183 & 0.921287 & 0.781381 & 0.814300 & 0.772304 & 0.801598 \\
UFPS & 0.773916 & 0.675494 & 0.721805 & 0.688531 & 0.716378 & 0.688415 \\
USP & 0.820321 & 0.806509 & 0.787834 & 0.768965 & 0.772304 & 0.752330 \\
USPS & 0.713698 & 1.177967 & 0.622529 & 1.232996 & 0.607190 & 1.147803 \\
\hline
\end{tabular}

Notes:

(1) The different models are defined in Table 1

(2) The computations are carried out in Eviews 
Table 6: Out-of-sample forecasting performance of US dollar/Euro rate models (2002Q2 to 2004Q1)

\begin{tabular}{l|cc|cc|cc}
\hline & \multicolumn{2}{|c|}{ RMSE/RMSE(RW) } & \multicolumn{2}{c|}{ MAE/MAE/(RW) } & \multicolumn{2}{c}{ MAPE/MAPE(RW) } \\
\hline & DVAR & VEC & DVAR & VEC & DVAR & VEC \\
\hline CFP & 1.080273 & 1.281610 & 1.066344 & 1.316790 & 0.994409 & 1.259207 \\
CFPS & 1.028249 & 1.134180 & 0.999109 & 1.149514 & 0.824586 & 0.867601 \\
CSP & 1.044611 & 1.558899 & 1.030821 & 1.644700 & 0.955420 & 1.331967 \\
CSPS & 0.962014 & 0.950607 & 0.955250 & 0.914869 & 0.758089 & 0.651334 \\
UFP & 1.103971 & 1.113497 & 1.120810 & 1.122861 & 0.997764 & 1.037125 \\
UFPS & 1.061914 & 1.025753 & 1.050321 & 1.003655 & 0.931415 & 0.897272 \\
USP & 0.960593 & 1.056518 & 0.894544 & 0.969112 & 1.163560 & 1.283361 \\
USPS & 0.947937 & 1.025196 & 0.892316 & 0.910234 & 1.084762 & 1.184285 \\
\hline
\end{tabular}

Notes:

(1) The model abbreviations are explained in Table 1

(2) The computations are carried out in Eviews 
Figure captions

Figure 1: Actual and forecasted series 
Figure 1: Actual and forecasted series

Panel A: Actual and forecasted series of US dollar/UK pound rate
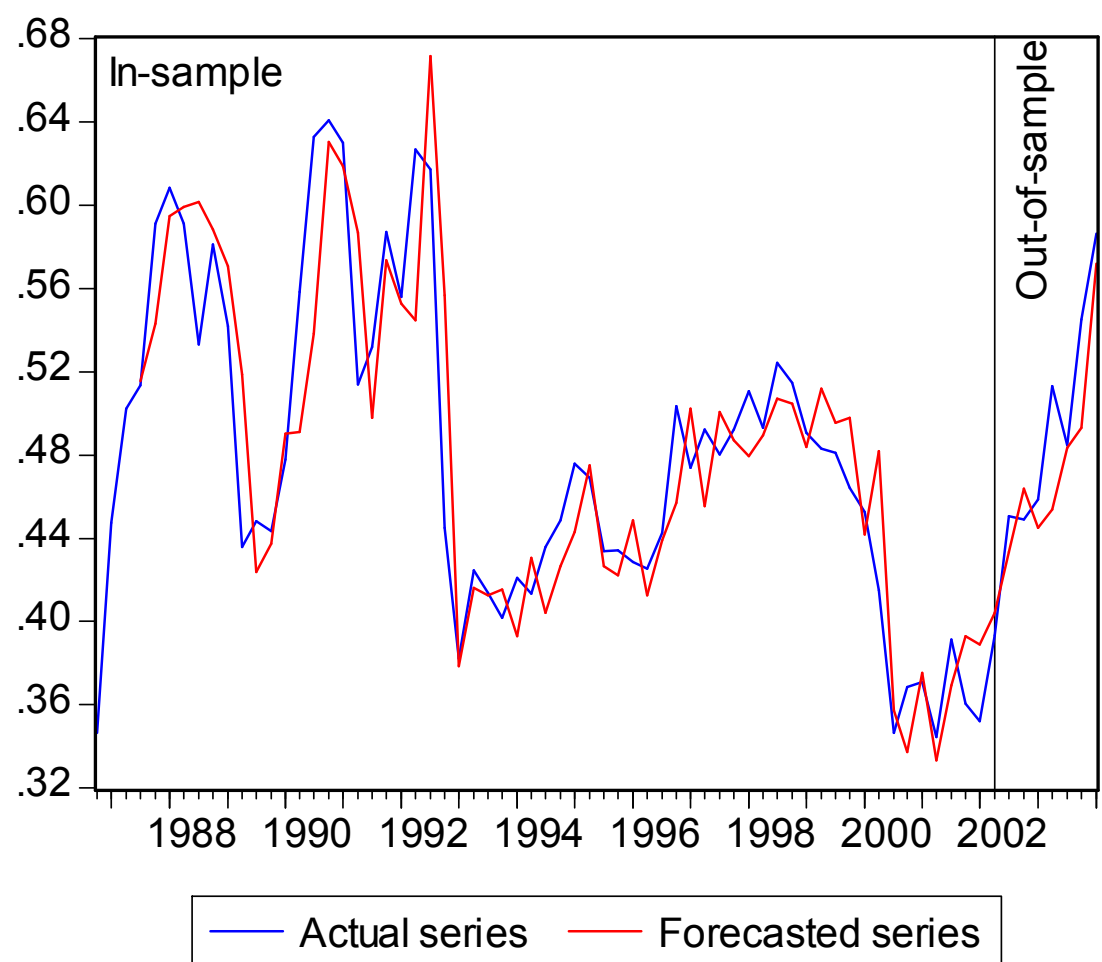

Panel B: Actual and forecasted series of US dollar/Euro rate 


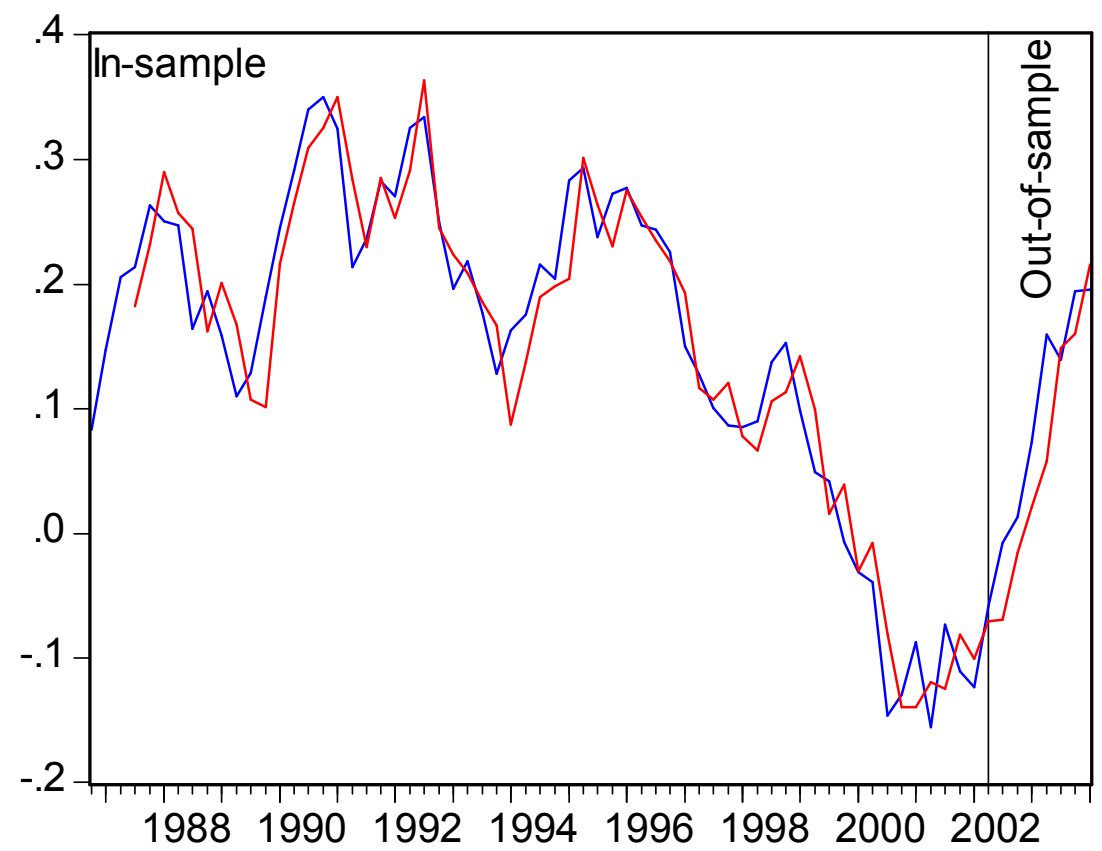

Actual series — Forecasted series 


\section{Footnotes}

${ }^{1}$ FRED is the Federal Reserve economic database (http://research.stlouisfed.org/fred2/)

${ }^{2}$ The data can be downloaded from http://www.sweepmeasures.com/

${ }^{3}$ The short term interest rate is updated by Livio Stracca to include more recent observations. 


\section{APPENDIX A:}

Table A1: VAR specification and misspecification test for US dollar/UK pound rate models

\begin{tabular}{llll}
\hline & VAR $(k)$ & $\operatorname{LM}(1)$ & $\operatorname{LM}(4)$ \\
\hline & & 26.97 & 15.57 \\
CFP & 2 & $(0.04)$ & $(0.48)$ \\
& & 26.64 & 15.37 \\
CFPS & 2 & $(0.05)$ & $(0.50)$ \\
& & 18.94 & 21.82 \\
CSP & 5 & $(0.80)$ & $(0.65)$ \\
& & 17.48 & 24.90 \\
CSPS & 5 & $(0.86)$ & $(0.47)$ \\
& & 56.61 & 35.37 \\
UFP & 2 & $(0.21)$ & $(0.93)$ \\
& & 69.86 & 37.66 \\
UFPS & 2 & $(0.03)$ & $(0.88)$ \\
& & 112.96 & 92.33 \\
USP & 3 & $(0.01)$ & $(0.18)$ \\
& & 118.28 & 88.54 \\
USPS & 2 & $(0.00)$ & $(0.26)$ \\
\hline
\end{tabular}

Notes:

(1) The model abbreviations are explained in Table 1.

(2) The computations are carried out using CATS and RATS.

Table A2: VAR specification and misspecification test for US dollar/Euro rate models

\begin{tabular}{llll}
\hline & VAR(k) & LM(1) & LM(4) \\
\hline & & 10.02 & 16.06 \\
CFP & 3 & $(0.87)$ & $(0.45)$ \\
& & 7.09 & 13.43 \\
CFPS & 3 & $(0.97)$ & $(0.64)$ \\
& & 12.49 & 36.38 \\
CSP & 3 & $(0.98)$ & $(0.07)$ \\
& & 25.06 & 37.25 \\
CSPS & 4 & $(0.46)$ & $(0.05)$ \\
& & 50.71 & 43.86 \\
UFP & 2 & $(0.41)$ & $(0.68)$ \\
& & 58.25 & 50.79 \\
UFPS & 2 & $(0.17)$ & $(0.40)$ \\
& & 88.35 & 69.66 \\
USP & 2 & $(0.27)$ & $(0.81)$ \\
& & 91.27 & 82.31 \\
USPS & 2 & $(0.20)$ & $(0.44)$ \\
\hline
\end{tabular}




\section{Notes:}

(1) The model abbreviations are explained in Table 1.

(2) The computations are carried out using CATS and RATS.

Tables A1 and A2 report the number of lags used to determine the rank and estimate the cointegrating vectors of each system for the US dollar/UK pound and US dollar/Euro rates respectively. The process of lag selection involved progressively increasing the lag length to make the residuals of the system white noise. Tables A1 and A2 also presents misspecification test statistics, in particular the Lagrange Multiplier (LM)-type of statistics for first-and fourth-order autocorrelation $(\operatorname{LM}(1)$ and $\operatorname{LM}(4))$, where the numbers in parentheses are $p$-values. The misspecification test indicates that for some models, those with a $p$-value less than 0.05 , there may be some serial correlation of order one. However, a further inspection of cross- and autocorrelograms of the estimated error terms in the VEC model suggests that there is no major problem with autocorrelation ${ }^{1}$. Thus, in general, the models seem to be well specified.

\footnotetext{
${ }^{1}$ Increasing the lag length did not improve the specification of the models.
} 


\section{APPENDIX B}

Table B1: Trace tests for cointegration rank for CFP models

\begin{tabular}{|c||c|c||c|c||c|}
\hline \multicolumn{1}{|c||}{} & \multicolumn{2}{c||}{$\begin{array}{c}\text { Models for the } \\
\text { US/UK rate }\end{array}$} & \multicolumn{2}{c|}{$\begin{array}{c}\text { Models for the } \\
\text { US/Euro rate }\end{array}$} & \\
\hline $\mathrm{H}_{0}: r$ & CFP & CFPS & CFP & CFPS & Trace 95\% \\
\hline 0 & 56.408 & 55.933 & 65.091 & 59.737 & 53.423 \\
\hline 1 & $\mathbf{2 7 . 9 8 9}$ & $\mathbf{2 9 . 5 1 2}$ & $\mathbf{3 4 . 3 7 4}$ & $\mathbf{3 2 . 6 8 1}$ & 34.795 \\
\hline 2 & 13.445 & 15.308 & 13.147 & 12.145 & 19.993 \\
\hline 3 & 1.712 & 2.437 & 1.108 & 1.806 & 9.133 \\
\hline
\end{tabular}

Notes:

(1) The model abbreviations are explained in Table 1.

(2) The bold letters indicate the first time the null hypothesis of $r$ cointgrating vectors is not rejected at the $5 \%$ level.

(3) The computations are carried out using CATS and RATS.

Table B2: Trace tests for cointegration rank for CSP models

\begin{tabular}{|c||c|c||c|c||c|}
\hline \multicolumn{1}{|c||}{} & \multicolumn{2}{c||}{$\begin{array}{c}\text { Models for the } \\
\text { US/UK rate }\end{array}$} & \multicolumn{2}{c|}{$\begin{array}{c}\text { Models for the } \\
\text { US/Euro rate }\end{array}$} & \\
\hline $\mathrm{H}_{0}: r$ & CSP & CSPS & CSP & CSPS & Trace $95 \%$ \\
\hline 0 & 120.658 & 114.112 & 108.399 & 94.618 & 75.737 \\
\hline 1 & 69.322 & 67.603 & 66.853 & 54.067 & 53.423 \\
\hline 2 & 35.110 & 34.974 & 36.259 & $\mathbf{3 2 . 1 0 6}$ & 34.795 \\
\hline 3 & $\mathbf{1 4 . 8 3 3}$ & $\mathbf{1 0 . 2 8 6}$ & $\mathbf{1 3 . 4 3 9}$ & 15.495 & 19.993 \\
\hline 4 & 3.419 & 2.792 & 2.637 & 4.271 & 9.133 \\
\hline
\end{tabular}

Notes:

(1) The model abbreviations are explained in Table 1.

(2) The bold letters indicate the first time the null hypothesis of $r$ cointgrating vectors is not rejected at the $5 \%$ level.

(3) The computations are carried out using CATS and RATS.

Table B3: Trace tests for cointegration rank for UFP models

\begin{tabular}{|c||c|c||c|c||c|}
\hline \multicolumn{1}{|c||}{} & \multicolumn{2}{c||}{$\begin{array}{c}\text { Models for the } \\
\text { US/UK rate }\end{array}$} & \multicolumn{2}{c|}{$\begin{array}{c}\text { Models for the } \\
\text { US/Euro rate }\end{array}$} & \\
\hline $\mathrm{H}_{0}: r$ & UFP & UFPS & UFP & UFPS & Trace 95\% \\
\hline 0 & 205.841 & 203.347 & 231.077 & 219.424 & 132.004 \\
\hline 1 & 142.147 & 143.091 & 159.830 & 147.069 & 101.838 \\
\hline 2 & 98.132 & 100.666 & 116.083 & 107.183 & 75.737 \\
\hline 3 & 62.876 & 62.175 & 73.761 & 73.633 & 53.423 \\
\hline 4 & 36.194 & 35.696 & 46.307 & 41.263 & 34.795 \\
\hline 5 & $\mathbf{1 3 . 3 4 8}$ & $\mathbf{1 1 . 8 7 3}$ & 22.263 & 21.196 & 19.993 \\
\hline 6 & 3.851 & 4.958 & $\mathbf{6 . 9 7 0}$ & $\mathbf{7 . 2 9 7}$ & 9.133 \\
\hline
\end{tabular}


Notes:

(1) The model abbreviations are explained in Table 1.

(2) The bold letters indicate the first time the null hypothesis of $r$ cointgrating vectors is not rejected at the $5 \%$ level.

(3) The computations are carried out using CATS and RATS.

Table B4: Trace tests for cointegration rank for USP models

\begin{tabular}{|c||c|c||c|c||c|}
\hline \multicolumn{1}{|c||}{} & \multicolumn{2}{c||}{$\begin{array}{c}\text { Models for the } \\
\text { US/UK rate }\end{array}$} & \multicolumn{2}{c|}{$\begin{array}{c}\text { Models for the } \\
\text { US/Euro rate }\end{array}$} & \\
\hline $\mathrm{H}_{0}: r$ & USP & USPS & USP & USPS & Trace 95\% \\
\hline 0 & 430.779 & 365.184 & 365.305 & 346.207 & 203.340 \\
\hline 1 & 326.310 & 278.236 & 269.052 & 241.523 & 165.732 \\
\hline 2 & 229.885 & 209.596 & 193.538 & 177.911 & 132.004 \\
\hline 3 & 159.385 & 145.597 & 140.726 & 125.907 & 101.838 \\
\hline 4 & 101.564 & 101.766 & 95.916 & 87.034 & 75.737 \\
\hline 5 & 61.378 & 64.089 & 61.808 & $\mathbf{5 1 . 6 6 4}$ & 53.423 \\
\hline 6 & 38.626 & 36.626 & 36.349 & 28.057 & 34.795 \\
\hline 7 & 21.828 & $\mathbf{1 7 . 4 0 0}$ & $\mathbf{1 8 . 6 3 1}$ & 15.080 & 19.993 \\
\hline 8 & $\mathbf{7 . 5 4 3}$ & 6.156 & 8.064 & 5.262 & 9.133 \\
\hline
\end{tabular}

\section{Notes:}

(1) The model abbreviations are explained in Table 1.

(2) The bold letters indicate the first time the null hypothesis of $r$ cointgrating vectors is not rejected at the $5 \%$ level.

(3) The computations are carried out using CATS and RATS. 